\title{
Microbial Resource Management for Ex Situ Biomethanation of Hydrogen at Alkaline $\mathrm{pH}$
}

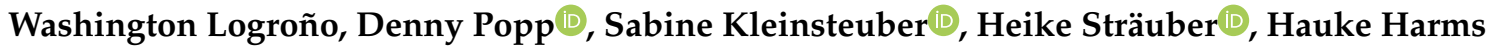 \\ and Marcell Nikolausz * \\ Department of Environmental Microbiology, Helmholtz Centre for Environmental Research-UFZ, \\ 04318 Leipzig, Germany; washington.logrono@ufz.de (W.L.); denny.popp@ufz.de (D.P.); \\ sabine.kleinsteuber@ufz.de (S.K.); heike.straeuber@ufz.de (H.S.); hauke.harms@ufz.de (H.H.) \\ * Correspondence: marcell.nikolausz@ufz.de; Tel.: +49-341-2434-566
}

Received: 19 March 2020; Accepted: 21 April 2020; Published: 24 April 2020 updates

\begin{abstract}
Biomethanation is a promising solution to convert $\mathrm{H}_{2}$ (produced from surplus electricity) and $\mathrm{CO}_{2}$ to $\mathrm{CH}_{4}$ by using hydrogenotrophic methanogens. In ex situ biomethanation with mixed cultures, homoacetogens and methanogens compete for $\mathrm{H}_{2} / \mathrm{CO}_{2}$. We enriched a hydrogenotrophic microbiota on $\mathrm{CO}_{2}$ and $\mathrm{H}_{2}$ as sole carbon and energy sources, respectively, to investigate these competing reactions. The microbial community structure and dynamics of bacteria and methanogenic archaea were evaluated through $16 \mathrm{~S}$ rRNA and $m c r A$ gene amplicon sequencing, respectively. Hydrogenotrophic methanogens and homoacetogens were enriched, as acetate was concomitantly produced alongside $\mathrm{CH}_{4}$. By controlling the media composition, especially changing the reducing agent, the formation of acetate was lowered and grid quality $\mathrm{CH}_{4}(\geq 97 \%)$ was obtained. Formate was identified as an intermediate that was produced and consumed during the bioprocess. Stirring intensities $\geq 1000 \mathrm{rpm}$ were detrimental, probably due to shear force stress. The predominating methanogens belonged to the genera Methanobacterium and Methanoculleus. The bacterial community was dominated by Lutispora. The methanogenic community was stable, whereas the bacterial community was more dynamic. Our results suggest that hydrogenotrophic communities can be steered towards the selective production of $\mathrm{CH}_{4}$ from $\mathrm{H}_{2} / \mathrm{CO}_{2}$ by adapting the media composition, the reducing agent and the stirring intensity.
\end{abstract}

Keywords: power-to-gas; energy storage; biogas upgrading; biomethane; formate; hydrogenotrophic methanogenesis; homoacetogenesis; Methanobacterium; Methanoculleus

\section{Introduction}

Renewable energy from wind power and photovoltaics increasingly leads to a temporary excess of electricity that cannot be handled by the grid and traditional storage infrastructure. Hence, technical solutions to store this energy, e.g., in the form of chemical energy carriers, are required. The power-to-gas (P2G) technology converts surplus power into a storable gas [1]. $\mathrm{H}_{2}$ can be generated through water electrolysis and subsequently injected and stored in the natural gas grid, though with certain limitations [2]. $\mathrm{CH}_{4}$ can also be produced from excess electricity in a two-stage process: $\mathrm{H}_{2}$ is first produced through water electrolysis and is then used in a methanation stage to reduce $\mathrm{CO}_{2}$ to $\mathrm{CH}_{4}$ [2]. Although the $\mathrm{H}_{2}$ production technology is quite advanced, it has some drawbacks concerning the long-term storage, safety and low energy density of $\mathrm{H}_{2}$, as well as the requirement for technical modifications of the natural gas grid. $\mathrm{CH}_{4}$, on the other hand, is very attractive because the storage and distribution infrastructure is already in place in many countries. $\mathrm{CH}_{4}$ can be readily injected into the gas grid and has a volumetric energy content of $36 \mathrm{MJ} \mathrm{m}^{-3}$, which is more than three times higher than that of $\mathrm{H}_{2}\left(10.88 \mathrm{MJ} \mathrm{m}^{-3}\right)$ [3]. 
Biogas is the product of anaerobic digestion (AD), which is a well-established commercial process and a key technology in the current and future renewable energy sector [4]. Biogas consists mainly of $\mathrm{CH}_{4}(40-75 \%)$ and $\mathrm{CO}_{2}(25-60 \%)$ and needs to be upgraded to biomethane by removing $\mathrm{CO}_{2}$ if injection into the gas grid is intended. Methods for biogas upgrading have been reviewed elsewhere [5-7]. Biological biogas upgrading (biomethanation) uses external $\mathrm{H}_{2}$ to convert the $\mathrm{CO}_{2}$ share of the biogas into additional $\mathrm{CH}_{4}$ via the $\mathrm{CO}_{2}$-reductive pathway of hydrogenotrophic methanogens. The biomethanation of $\mathrm{H}_{2}$ is an emerging technology that appears to be advantageous over the catalyst-based chemical methanation (Sabatier reaction) due to its milder reaction conditions [6]. This bioprocess can be performed by pure methanogenic strains [8] or mixed cultures [6]. The latter may have certain economic and process advantages over pure cultures [9].

According to Kougias et al. [10] and Rittmann [11], biomethanation of $\mathrm{H}_{2}$ can be done in three ways: in situ, ex situ and by a hybrid process. In the in situ process, $\mathrm{H}_{2}$ is injected into the main anaerobic digester or post-digester of a biogas plant to reduce $\mathrm{CO}_{2}$ and thereby increase the $\mathrm{CH}_{4}$ content of the biogas. In the ex situ process, biogas or $\mathrm{CO}_{2}$ reacts with $\mathrm{H}_{2}$ in a bioreactor that is separate from the AD process. The hybrid process couples partial biogas upgrading in the main $\mathrm{AD}$ reactor (in situ) with a final upgrading step in a separate reactor (ex situ). Defining the system to be investigated according to the abovementioned categories is important for comparisons in terms of efficiency and microbiota. An ex situ reactor could provide a defined ecological niche to enrich specialized hydrogenotrophic microbiota with an autotrophic metabolism (methanogenesis and homoacetogenesis). It can be hypothesized that the inoculum, the operation temperature and the continuous supply of $\mathrm{H}_{2}$ play important roles in shaping the microbial community towards the predominance of either hydrogenotrophic methanogens or homoacetogenic bacteria.

If a complex inoculum is used to perform the ex situ biomethanation of $\mathrm{H}_{2}$, acetate could be synthesized from $\mathrm{H}_{2}$ and $\mathrm{CO}_{2}$ via the Wood-Ljungdahl pathway concomitantly with $\mathrm{CH}_{4}$ formation. Acetate synthesis during ex situ biomethanation represents a problem, as it is an undesirable carbon and electron sink when $\mathrm{CH}_{4}$ is the target molecule. It is therefore necessary to manage the microbiota towards selective $\mathrm{CH}_{4}$ production. In environmental biotechnology, the term microbial resource management implies finding strategies to obtain and maintain a highly performing community [12]. The understanding of metabolic processes in complex communities imposes a great challenge that could be overcome by establishing enrichment cultures to investigate the essential metabolic functions without the need for pure cultures [13]. Enriched mixed cultures could be simple enough to investigate individual community members [14] and represent opportunities to grow uncultivable microbes [15], including those requiring syntrophic partners [16]. Ex situ biomethanation studies have found Methanobacteriales [10,17-23], Methanomicrobiales [10,24] and Methanococcales [24] to be the dominant orders. Methanothermobacter thermautotrophicus was the dominant methanogen in three different reactor configurations [10]. In the bacterial domain, Firmicutes [10,21,25,26], Bacteroidetes [10], Synergistetes [21] and Proteobacteria [25] were the dominant phyla.

Sludge from biogas reactors or wastewater anaerobic granules has been used as an inoculum source $[10,17,19,24,27-31]$. From a microbiological point of view, certain process parameters such as temperature and $\mathrm{pH}$, substrate characteristics and inoculum sources define the community structure and dominant members of the microbiota. An ex situ study comparing different reactor configurations reached $\mathrm{CH}_{4}$ concentrations of more than $98 \%$; however, acetic acid accumulated to concentrations of $\sim 4 \mathrm{~g} \mathrm{~L}^{-1}$ and the $\mathrm{pH}$ values were $\geq 8$ [10]. Similar $\mathrm{pH}$ values ranging from seven to $\geq 8$ were also reported in a continuous stirred tank reactor (CSTR) for ex situ biomethanation [32]. Ex situ biomethanation studies have operated at slightly alkaline $\mathrm{pH}$, but microbial enrichment studies under such conditions are still missing.

In the present study, we explore the ex situ biomethanation of $\mathrm{H}_{2}$ at alkaline $\mathrm{pH}$ through an enrichment process. The aim of the enrichment strategy was to better understand the microbial community dynamics assessed by the amplicon sequencing of $16 \mathrm{~S}$ rRNA and mcrA genes to follow the competition between methanogenesis and homoacetogenesis during ex situ biomethanation. 
Hydrogenotrophic methanogenesis has been reported as the major methanogenic pathway under high nitrogen load and high ammonia concentration [33-35]. Thus, we used the digestate of a laboratory-scale biogas reactor (CSTR) treating a nitrogen-rich substrate (dried distiller grains with solubles (DDGS)) as the inoculum source for the long-term enrichment of a hydrogenotrophic microbiota that performs ex situ biomethanation. Additionally, the effects of media components, such as yeast extract and reducing agent, as well as of the stirring intensity on the $\mathrm{H}_{2}$ and $\mathrm{CO}_{2}$ metabolism, were investigated.

\section{Materials and Methods}

\subsection{Inoculum}

Anaerobic sludge from a mesophilic $\left(38^{\circ} \mathrm{C}\right)$ laboratory-scale CSTR treating DDGS was sieved using a 400- $\mu \mathrm{m}$ mesh sieve under nitrogen flow. The liquid inoculum was degassed at $38{ }^{\circ} \mathrm{C}$ for 7 days before use. The basic characteristics are the mean values of triplicate measurements as follows: total solids (TS), 3.4\%; volatile solids (VS), 70.1\% ${ }_{\mathrm{TS}} ; \mathrm{pH}, 7.5$.

\subsection{Growth Medium}

Modified mineral medium DSMZ1036 containing yeast extract $\left(0.2 \mathrm{~g} \mathrm{~L}^{-1}\right)$, as described by Porsch and colleagues [36], was used for the enrichment and is designated as medium A hereafter. For further experiments, the medium was used in two variants: medium B did not contain yeast extract, but was supplemented with a vitamin solution, as described by [37], and cysteine- $\mathrm{HCl}$ as reducing agent in the same concentration as in medium A. Medium C contained vitamins, like medium B, but sodium sulfide as a reducing agent, as described by [37]. After preparing the media as described in Text S1 (Supplementary Materials), the $\mathrm{pH}$ for all media variations was adjusted to nine with a sterile anoxic stock solution of $2 \mathrm{M} \mathrm{KOH}$.

\subsection{Enrichment Setup}

Strict anaerobic techniques were thoroughly applied in this study. Sterile anoxic bottles were prepared as described in Text S2 (Supplementary Materials) prior to medium dispensing and inoculation. The gas volume/liquid volume ratio was maintained at three for all experiments, regardless of the size of the bottle, unless stated otherwise. The experiments were conducted with four biological replicates in the first stage (gas feeding of the anaerobic sludge) and triplicates in the second stage (enrichment in the mineral medium). A detailed chronology of the culture transfers is provided in Table S4.

The setup in the first stage was assembled in an anaerobic chamber. Serum bottles of $219.5 \mathrm{~mL}$ volume were filled with $50 \mathrm{~mL}$ degassed inoculum, sealed with butyl rubber stoppers and crimped with aluminum caps. The gas phase of the serum bottles was replaced by $\mathrm{H}_{2}(80 \%)$ and $\mathrm{CO}_{2}$ (20\%). All bottles receiving $\mathrm{H}_{2}$ and $\mathrm{CO}_{2}$ were operated in fed-batch mode and pressurized daily to 2.2 bar for approximately five months. Bottles containing the inoculum and a nitrogen atmosphere (not pressurized) were used as controls to account for the residual biogas production. Detailed information about headspace flushing and pressurization is given in Text S2.

In the second stage, medium A was used to enrich a particle-free culture by six subsequent culture transfers in fresh medium bottles by inoculating the content of the preceding culture transfer $(10 \%, v / v)$. One randomly selected replicate from the first stage served as the inoculum to start the bottles for the second stage. Anoxic medium A (45 mL) was dispensed to sterile, anoxic serum bottles and left overnight in an incubator at $37^{\circ} \mathrm{C}$ to reduce any oxygen traces that entered the bottles during medium dispensing. Next, the bottles were inoculated with $5 \mathrm{~mL}$ culture from the first stage. Biological controls for determining residual biogas production (containing inoculum but with $\mathrm{N}_{2}$ gas phase), as well as sterile controls (not inoculated, but with either $\mathrm{H}_{2} / \mathrm{CO}_{2}$ or $\mathrm{N}_{2}$ gas phase), were also set up. The bottles were fed with a gaseous substrate, as described above, and incubated at $37.4{ }^{\circ} \mathrm{C}$ in an orbital shaking incubator (IKA KS 4000 ic control, IKA ${ }^{\circledR}$-Werke GmbH \& Co. KG, Biberach an der Riss, Germany) at $200 \mathrm{rpm}$. 


\subsection{Cultivation Experiments}

In a series of four independent experiments, the effects of medium composition and stirring intensity on biomethanation, biomass growth, and production of volatile fatty acids (VFA) were investigated. Experiments were conducted in 1-L pressure-resistant Duran bottles (Schott AG, Mainz, Germany). Bottles were inoculated with $10 \%(v / v)$ pre-culture (21 days old second stage enrichment culture, 11th transfer (T11)) and incubated at $37{ }^{\circ} \mathrm{C}$ under constant orbital shaking at $200 \mathrm{rpm}$. The experiments were conducted in duplicate and stepwise to investigate the effect of the medium composition (media A, B and C as described in Section 2.2). The gas consumption and production, as well as the development of biomass and VFA production, were frequently monitored.

After the optimal medium had been determined, we tested the effect of the stirring intensity on the $\mathrm{CH}_{4}$ production and $\mathrm{H}_{2} / \mathrm{CO}_{2}$ consumption. Instead of shaking, the bottles were stirred with magnetic stirrers (top plate diameter of $145 \mathrm{~mm}$, speed range from 100 to $1400 \mathrm{rpm}$; Heidolph, Germany) and new magnetic bars (50 mm $\times 8 \mathrm{~mm}$, LABSOLUTE, Th. Geyer, Renningen, Germany) and incubated at $38^{\circ} \mathrm{C}$. To reduce the detrimental effects of shear forces on the cells, the liquid volume was increased to $500 \mathrm{~mL}$, corresponding to a gas volume/liquid volume ratio of one. The experiments were conducted three times with duplicates $(n=6)$.

Flushing and pressurizing, as well as pressure determination and the sampling of the gas and liquid phases, were done as described above (see also Text S2) for all four experiments.

\subsection{Microbial Community Analysis}

Samples for community analysis were taken from the inoculum (S), as well as after one month (1 $\mathrm{M})$ and 5 months $(5 \mathrm{M})$ of fed-batch feeding during the first stage of the enrichment. Samples from the second stage were taken at the end of the first (T1), third (T3), and sixth (T6) culture transfer. Liquid samples of $1.5 \mathrm{~mL}$ were withdrawn from each bottle with a nitrogen-flushed syringe (Text S2) and centrifuged at $4{ }^{\circ} \mathrm{C}$ and $20,817 \times g$ for $10 \mathrm{~min}$. Pellets were stored at $-20^{\circ} \mathrm{C}$ until DNA extraction. DNA was extracted with the NucleoSpin ${ }^{\circledR}$ Soil Kit (MACHEREY-NAGEL GmbH \& Co. KG, Biberach an der Riss, Germany) using SL2 buffer and enhancer solution. The quality and quantity of extracted DNA were verified via gel electrophoresis ( $0.8 \%$ agarose) and photometrically using a NanoDrop ND 1000 spectral photometer (Thermo Fisher Scientific, Waltham, MA, USA). Extracted DNA was stored at $-20{ }^{\circ} \mathrm{C}$ until use. The microbial community composition was analyzed by the amplicon sequencing of $m c r A$ genes for methanogens and 16S rRNA genes for bacteria.

In order to analyze the bacterial communities, the V3-V4 region of the 16S rRNA genes was amplified using the universal primers 341f (5' -CCT ACG GGN GGC WGC AG-3') and 785r (5'-GAC TAC HVG GGT ATC TAA KCC-3') described by Klindworth et al. [38]. For the analysis of the methanogenic communities, the mlas (5'-GGT GGT GTM GGD TTC ACM CAR TA-3') and mcrA-rev (5'-CGT TCA TBG CGT AGT TVG GRT AGT-3') primers were used as described by Steinberg and Regan [39]. All primers contained Illumina MiSeq-specific overhangs. Amplicon libraries were prepared and sequenced on the Illumina MiSeq platform using the MiSeq Reagent Kit v3 with $2 \times 300$ cycles. Demultiplexed raw sequence data were deposited at the EMBL European Nucleotide Archive (ENA) under the study accession number PRJEB36972 (http://www.ebi.ac.uk/ena/data/view/PRJEB36972).

Primer sequences were clipped from demultiplexed and adapter-free reads using Cutadapt v1.18 [40]. Further sequence analysis was performed using QIIME2 v2019.1 [41]. Sequences were trimmed, denoised and merged using the dada2 plugin [42]. For 16S rRNA gene analysis, forward and reverse reads were truncated at $270 \mathrm{bp}$ and $240 \mathrm{bp}$, respectively. For $m c r A$ gene analysis, reads were truncated at $270 \mathrm{bp}$ and $230 \mathrm{bp}$, respectively. Maximum expected errors were set to two, which is the default value. Chimeras were removed in the default consensus mode of the dada2 plugin. The resulting feature sequences of $16 \mathrm{~S}$ rRNA gene analysis were classified against the MiDAS (Microbial Database for Activated Sludge) database v2.1 [43], trimmed to the region covered by the $341 \mathrm{f}$ and $785 \mathrm{r}$ primers. For $m c r A$ gene analysis, a taxonomy database was created by using $m c r A$ sequences from the RDP (Ribosomal Database Project) FunGene database [44]. For this purpose, $m c r A$ sequences 
were downloaded (2878 sequences on 21st of January 2019), sequences from uncultured organisms and metagenomic sequences were removed, and taxonomic information was formatted, resulting in 385 sequences used for the classification. As the primer combination 341f/785r also amplifies archaeal $16 \mathrm{~S}$ rRNA genes, archaeal reads were removed from further analyses of the 16S rRNA genes and bacterial read counts were normalized to $100 \%$.

\subsection{Analytical Methods}

To determine the TS content of the inoculum, samples were dried at $105^{\circ} \mathrm{C}$ for $24 \mathrm{~h}$ and the mass was recorded. The TS value was calculated from the mass difference between the fresh and dried sample. Subsequently, the samples were incinerated at $550{ }^{\circ} \mathrm{C}$ in a muffle furnace for $2 \mathrm{~h}$ and the mass was recorded. The VS value was calculated based on the mass difference between dried and incinerated samples. The mean values of triplicate measurements are presented.

To determine the headspace gas composition, $1 \mathrm{~mL}$ gas sample was withdrawn with a syringe and injected into an argon pre-flushed glass vial of $20 \mathrm{~mL}$ (Text S2). The gas samples were measured via gas chromatography equipped with an autosampler in a Perkin Elmer GC. The GC was equipped with HayeSep N/Mole Sieve 13X columns and a thermal conductivity detector. The oven and detector temperatures were $60^{\circ} \mathrm{C}$ and $200{ }^{\circ} \mathrm{C}$, respectively. The carrier gas was argon. Every gas sample was analyzed immediately or within $24 \mathrm{~h}$ after sampling.

The relative pressure in the bottles was measured with a digital manometer (Text S2). The gas amount in the bottles was calculated according to Equation (1). Standard conditions were considered for calculations $(p=1.01325 \mathrm{bar}, T=298.15 \mathrm{~K})$. The consumption and production rates of gases $\left(\mathrm{H}_{2}, \mathrm{CO}_{2}\right.$, and $\mathrm{CH}_{4}$ ) were determined from the linear slope of at least three continuous measurements and are given in mmol gas per liter liquid volume per hour $\left(\mathrm{mmol} \mathrm{L}^{-1} \mathrm{~h}^{-1}\right)$.

$$
\operatorname{Gas}_{(X i)}[\mathrm{mmol}]=\frac{P_{a b s}[\mathrm{mbar}] \times \frac{\operatorname{Gas}_{(X i)}[\%]}{100} \times V_{h}[\mathrm{~mL}]}{R \times T[\mathrm{~K}]} \times 1000
$$

where $X i$ refers to the gas in question, $P_{a b s}$ is the absolute pressure inside the bottle, $V_{h}$ is the headspace volume of the cultivation bottle $(169.5 \mathrm{~mL}), R$ is the universal gas constant $\left(8.314 \times 10^{4} \mathrm{mbar} \mathrm{cm}^{3} \mathrm{~mol}^{-1} \mathrm{~K}^{-1}\right)$, and $\mathrm{T}$ is the standard temperature.

For measuring the concentration of VFA (formic, acetic, propionic and butyric acid), the supernatants from liquid samples were filtered through a membrane filter with $0.2 \mu \mathrm{m}$ pore size (13 mm; LABSOLUTE, Th. Geyer GmbH, Hamburg, Germany) and stored at $-20{ }^{\circ} \mathrm{C}$ or analyzed immediately. When needed, appropriate dilutions were prepared with deionized water and the samples were analyzed by using high performance liquid chromatography (HPLC; Shimadzu Scientific Instruments, US) equipped with a refractive index detector (RID) L-2490 and an ICSep column COREGEL87H3 (Transgenomic Inc., Omaha, NE, USA). The sample volume for HPLC measurement was $200 \mu \mathrm{L}$ and the injection volume was $20 \mu \mathrm{L}$. The HPLC measurements were done with $5 \mathrm{mM}$ $\mathrm{H}_{2} \mathrm{SO}_{4}$ as the eluent at a flow rate of $0.7 \mathrm{~mL} \mathrm{~min}^{-1}$.

The $\mathrm{pH}$ value of the broth was measured in $200 \mu \mathrm{L}$ liquid samples using a mini-pH meter (ISFET pH meter S2K922, ISFETCOM Co., Ltd., Hidaka, Japan) and the value was recorded after $90 \mathrm{s.}$ For particular experiments with mediums $\mathrm{B}$ and $\mathrm{C}$, the $\mathrm{pH}$ was determined as aforementioned after a centrifugation step at $20,817 \times g, 4^{\circ} \mathrm{C}, 10 \mathrm{~min}$.

\subsection{Statistical Analysis}

The $\mathrm{CH}_{4}$ concentrations of the two stages were compared when the gas conversion and production was stable throughout several feeding cycles (variation was less than $10 \%$ in at least ten consecutive batch-cycle feedings) by means of analysis of variance (ANOVA). Tukey's post-hoc test was used for multiple comparisons with a confidence level of 0.05. RStudio [45], Graphpad (Graphpad Software, Inc., San Diego, CA, USA) or Microsoft Excel were used to compute the data. Microbial community 
composition data were analyzed by principal coordinate analysis ( $\mathrm{PCOA}$ ) based on Bray-Curtis distances of relative abundance in addition to the absence and presence using the phyloseq package [41] version 1.30.0 in R [46] version 3.6.1. PCoA was plotted using the ggplot2 package [47] version 3.2.1.

\section{Results and Discussion}

\subsection{Enrichment of the Hydrogenotrophic Community and Biomethanation Performance}

During the first stage of the enrichment, $\mathrm{CH}_{4}$ was formed within $24 \mathrm{~h}$ upon $\mathrm{H}_{2} / \mathrm{CO}_{2}$ feeding, and the process was stable for $\sim 5$ months. The rapid gas substrate conversion indicated high hydrogenotrophic methanogenesis activity in the inoculum. This observation is in agreement with a previous study [48]. However, the highest $\mathrm{CH}_{4}$ concentration between feeding cycles was only $\sim 90 \%$ (Figure $\mathrm{S} 1$ ). In the second stage of the enrichment, the $\mathrm{CH}_{4}$ concentrations in six successive transfers (T1-T6) were as high as in the bioreactors working with sludge in the first stage (Table 1). The $\mathrm{CH}_{4}$ concentration was $6 \%$ lower than the one described by Luo and Angelidaki [17], but was similar to that observed in another study [20].

Particle-free cultures were obtained after the third transfer and, therefore, the cell biomass from T3-T6 could be followed by spectrophotometry via optical density $\left(\mathrm{OD}_{600}\right)$ (Figure S2). On average, each transfer from $\mathrm{T} 3$ to $\mathrm{T} 6$ started with a biomass of $91 \pm 22 \mathrm{mg} \mathrm{L}^{-1}$, whereas the final biomass was, on average, $579 \pm 26 \mathrm{mg} \mathrm{L}^{-1}$. In terms of biomass and gas composition, no significant difference $(p \leq 0.05)$ among transfers was found when comparing the end points of each transfer (Table 1). At the end of each culture transfer, the $\mathrm{pH}$ was $\sim 8$, a value similar to that reported by Kougias and colleagues [10]. Acetate was found in considerable concentrations from T1 to T5, but neither in the seed sludge (after $\sim 5$ months) nor in T6 (see Table 1), indicating that homoacetogenesis was a concomitant reaction alongside methanogenesis in our enriched hydrogenotrophic community. The variation in acetate concentrations among transfers could be associated with the cultivation time, especially for the particle-free enrichment cultures ( $\mathrm{T} 5$ and $\mathrm{T} 6$ ), where the acetate concentration was generally low and the cultivation time was long.

The decrease in the acetate concentration at the end of the culture transfer (T6) suggests decreased homoacetogenic activity or increased acetate utilization via syntrophic acetate oxidation (SAO), since acetotrophic methanogens were absent in our enrichment cultures (see Section 3.2). Another explanation for the decrease could be acetate assimilation to build up microbial biomass, since hydrogenotrophic microbes can use an organic carbon source such as acetate when available. It has been reported that acetate is central to the carbon metabolism of autotrophic and heterotrophic microbes [49]. Despite the variations in acetate concentration, the observed values throughout the culture transfers were similar to those reported in other studies $[10,19,24,26,30]$. Since acetate was the main side product, the kinetics of acetate consumption were assessed in more detail during one batch cycle of feeding when the culture (T1) presented stable gas consumption in several consecutive batch cycles (Figure S3). Acetate was consumed during the first $7 \mathrm{~h}$ ( $4 \%$ consumption likely to build biomass) and then its concentration increased again (1\% increase), although the final concentration was $3 \%$ less than the initial concentration. Propionate and butyrate were also detected and the highest concentrations were found in T1 and T3. However, their concentrations decreased over the consecutive transfers (Table 1). It is most likely that this effect was also related to the cultivation time of the culture transfers. 
Table 1. Summary of process parameters during the enrichment in the first stage with sludge and in the second stage with six culture transfers (T1-T6).

\begin{tabular}{|c|c|c|c|c|c|c|c|}
\hline Sample & Sludge ${ }^{b}$ & $\mathrm{~T}^{\mathrm{c}}$ & $\mathrm{T} 2^{\mathrm{c}}$ & $T 3^{c}$ & $T 4^{c}$ & $T 5^{c}$ & $T 6^{c}$ \\
\hline Days of incubation & 167 & 56 & 27 & 22 & 24 & 28 & 40 \\
\hline $\mathrm{CH}_{4}(\%)^{\mathrm{a}}$ & $85.17 \pm 4.5$ & $86.99 \pm 5.4$ & $88.04 \pm 3.2$ & $87.48 \pm 4.7$ & $88.00 \pm 2.3$ & $87.21 \pm 4.1$ & $87.47 \pm 2.5$ \\
\hline $\begin{array}{l}\text { Biomass concentration } \\
\text { start }\left(\mathrm{mg} \mathrm{L}^{-1}\right)^{\mathrm{d}}\end{array}$ & - & - & - & $92.2 \pm 11.73$ & $91.4 \pm 2.56$ & $90.3 \pm 17.79$ & $88.6 \pm 10.48$ \\
\hline end $\left(\mathrm{mg} \mathrm{L}^{-1}\right)^{\mathrm{d}}$ & - & - & - & $609.1 \pm 33.57$ & $548.2 \pm 30.22$ & $570.7 \pm 31.46$ & $588.2 \pm 32.42$ \\
\hline $\mathrm{pH}$ (start) & $8.0 \pm 0.1$ & $9.0 \pm 0.1$ & $9.0 \pm 0.1$ & $9.0 \pm 0.1$ & $9.0 \pm 0.1$ & $9.0 \pm 0.1$ & $9.0 \pm 0.1$ \\
\hline $\mathrm{pH}$ (end) & $8.5 \pm 0.2$ & $8.4 \pm 0.1$ & $8.3 \pm 0.2$ & $7.9 \pm 0.1$ & $8.1 \pm 0.1$ & $8.0 \pm 0.1$ & $8.1 \pm 0.1$ \\
\hline Acetate $\left(\mathrm{mg} \mathrm{L}^{-1}\right)$ & $123.5 \pm 7.8$ & $2089 \pm 194$ & $970.8 \pm 54.6$ & $1922 \pm 398$ & $2053 \pm 156$ & $886.9 \pm 170.9$ & $122.7 \pm 20.1$ \\
\hline Propionate $\left(\mathrm{mg} \mathrm{L}^{-1}\right)$ & $0.0 \pm 0.0$ & $26.03 \pm 2.3$ & $492.1 \pm 16.4$ & $185.9 \pm 18.3$ & $188.3 \pm 37.9$ & $135.9 \pm 3.9$ & $92.15 \pm 3.7$ \\
\hline Butyrate $\left(\mathrm{mg} \mathrm{L}^{-1}\right)$ & $0.0 \pm 0.0$ & $56.33 \pm 19.2$ & $0.0 \pm 0.0$ & $147.2 \pm 13.2$ & $84.04 \pm 10.26$ & $28.1 \pm 0.84$ & $25.89 \pm 1.4$ \\
\hline
\end{tabular}

a Concentration measured when the gas production was stable (mean and standard deviation, $n=17$ ). ${ }^{\mathrm{b}}$ Four biological replicates. Mean and standard deviation are shown.

${ }^{c}$ Three biological replicates. Mean and standard deviation are shown. ${ }^{d}$ Experimental conversion factor for biomass quantification: $1 \mathrm{OD}_{600}=0.423 \mathrm{~g} \mathrm{~L}-1$ dry weight. Details are given in Figure S3. 


\subsection{Microbial Community Structure and Dynamics}

Feeding the complex community with a rather simple substrate probably reduced the microbial diversity, as shown by Kougias and colleagues [10], but it could still maintain a number of cooperative as well as competing functional groups. The effect of $\mathrm{H}_{2} / \mathrm{CO}_{2}$ as selection factor shaping the bacterial and methanogenic communities resulted in a dynamic process throughout the enrichment, as visualized by PCoA (see the time trajectory in Figure 1). The first two axes explained $64 \%$ and $98 \%$ of the variance for the bacterial (Figure 1A) and methanogenic (Figure 1B) communities, respectively. Hence, a two-dimensional plot is sufficient to represent the relationship between the samples. Microbial communities were grouped according to transfers, which means that the communities of the same transfer were quite similar, but were different from those of the other transfers.
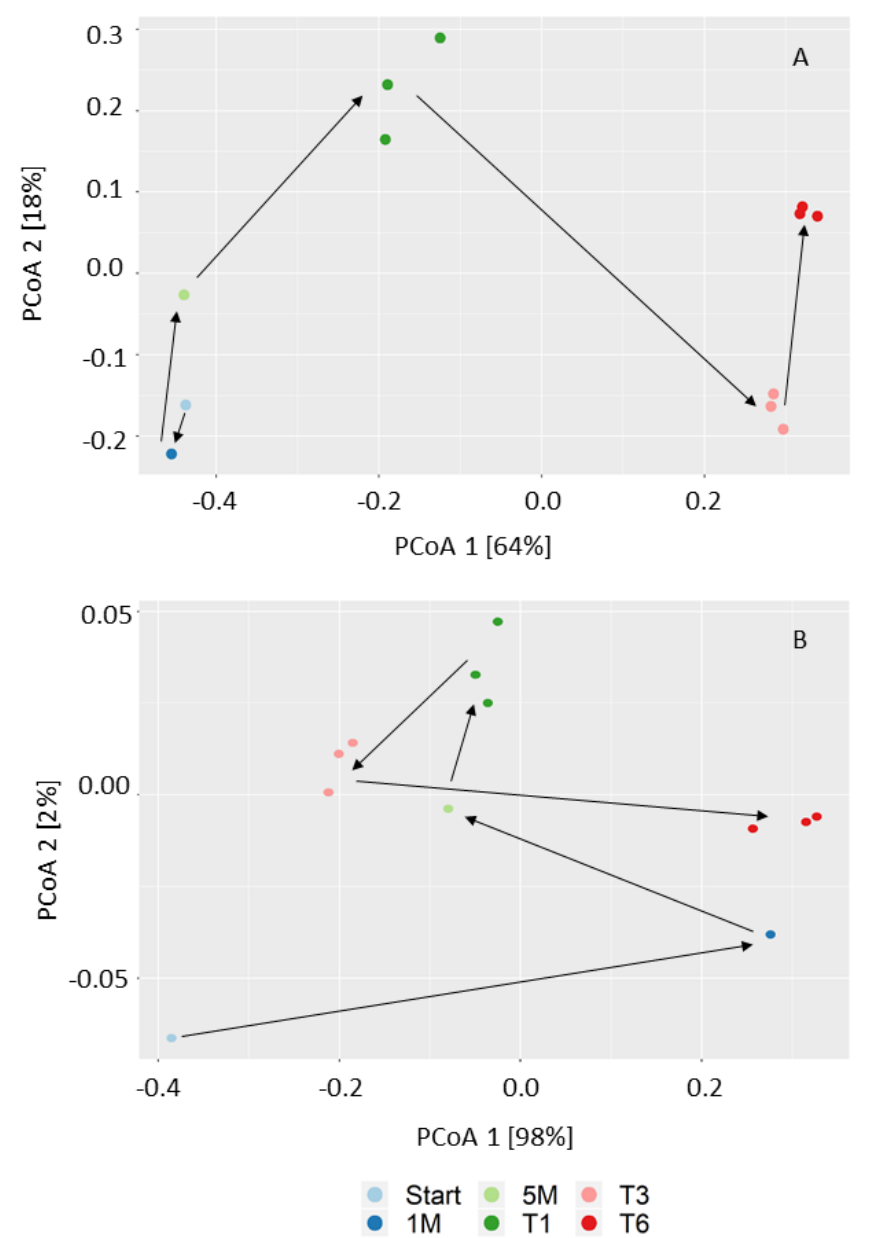

Figure 1. Principal coordinate analysis (PCoA) based on Bray-Curtis distances showing the microbial community shift during the enrichment. (A) Bacterial community (16S rRNA gene amplicon sequences) and (B) methanogenic community ( $m c r A$ gene amplicon sequences). The labels of the figure are as follows: inoculum (Start), one month ( $1 \mathrm{M}), 5$ months $(5 \mathrm{M})$ after fed-batch feeding during the first stage; first transfer (T1), third transfer (T3), and sixth transfer (T6) after fed-batch feeding in the second stage.

As expected, based on the high ammonia level $\left(5.84 \mathrm{~g} \mathrm{~L}^{-1} \mathrm{NH}_{4}-\mathrm{N}\right)$ of the source digester, the methanogenic community in the inoculum was dominated by hydrogenotrophic methanogens affiliated to the genus Methanobacterium (Figure 2), which is in agreement with other studies on high ammonia level reactors [33-35]. Methanogens affiliated to the genus Methanosarcina were also present in the inoculum, but disappeared after one month of $\mathrm{H}_{2} / \mathrm{CO}_{2}$ feeding, despite their versatility in substrate utilization. It was proposed that $\mathrm{H}_{2}$ feeding exerts a selection pressure that enriches hydrogenotrophic 
methanogens $[21,25]$, which could explain the disappearance of Methanosarcina and the complete dominance of strictly hydrogenotrophic methanogens in the enrichment. The $\mathrm{H}_{2}$ uptake rate was reported to be one order of magnitude higher for the strict hydrogenotrophic methanogen Methanococcus maripaludis [50] than for the versatile methanogen Methanosarcina barkeri [51]; therefore, this aspect may also explain why Methanosarcina disappeared despite the fact that it can grow on $\mathrm{H}_{2} / \mathrm{CO}_{2}$.

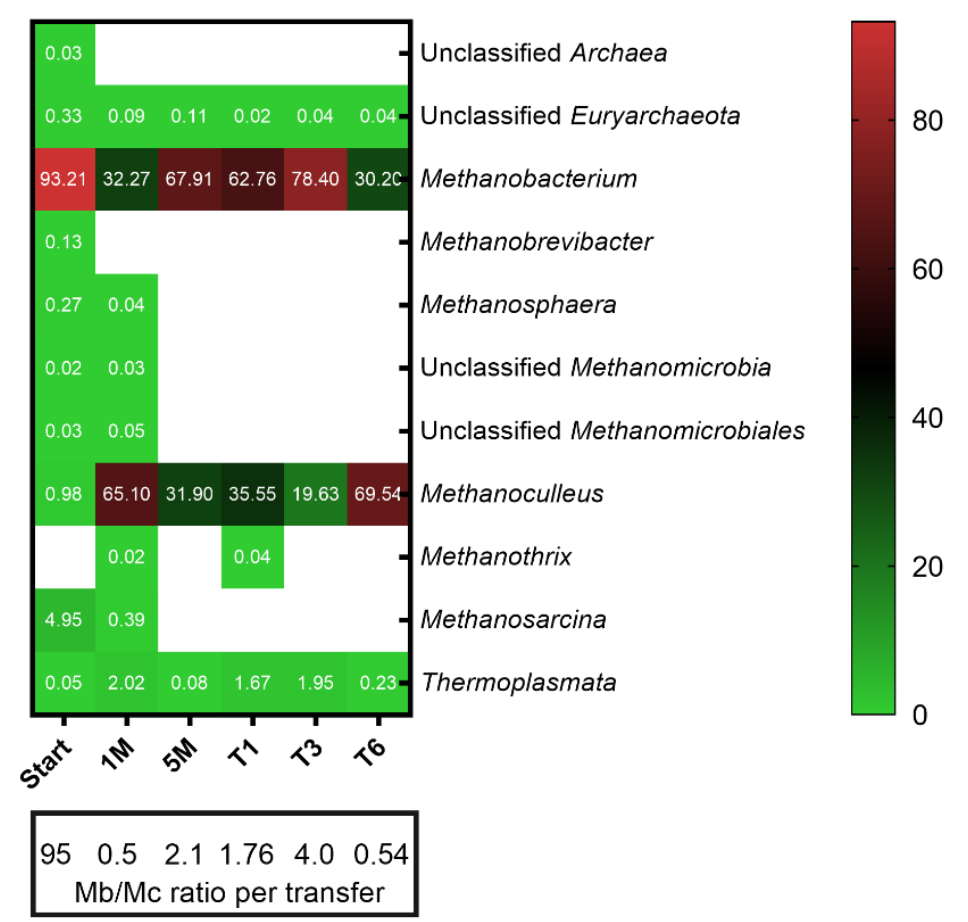

Figure 2. Methanogenic community structure in different stages of the enrichment. Taxa with a relative abundance less than $0.01 \%$ were filtered out from all samples. Numbers represent the relative abundance in percent and blank space indicates the absence of the respective taxa. The ratio of the most dominant methanogens, Methanobacterium (Mb) and Methanoculleus (Mc), among transfers is shown. Mean values of three biological replicates are presented for T1, T3 and T6 whereas single values are shown for Start, $1 \mathrm{M}$ and $5 \mathrm{M}$.

The species of the genus Methanoculleus dominated (65\% of the total methanogenic community) after one month of fed-batch feeding of $\mathrm{H}_{2} / \mathrm{CO}_{2}$, but decreased to $32 \%$ after 5 months during the first stage of the enrichment. In the second stage, Methanobacterium dominated the methanogenic community in the inoculum (5M), but after $\mathrm{H}_{2} / \mathrm{CO}_{2}$ fed-batch feeding, Methanoculleus increased in relative abundance and eventually became the dominant methanogen (T6). Other studies reported Methanoculleus [25] and Methanobacteriales to be the dominant methanogenic taxa [17], regardless of the reactor configuration. Members of the order Methanomassiliicoccales (class Thermoplasmata Figure 2) were present until the end of the experiment, with low relative abundance, as reported in another ex situ biomethanation study [26].

In reactors operated under thermophilic conditions $\left(\geq 55{ }^{\circ} \mathrm{C}\right)$, Methanothermobacter and Methanoculleus dominated the methanogenic community $[10,24,25,52]$. Consequently, we suggest that, regardless of the operational temperature, methanogens affiliated to Methanomicrobiaceae and Methanobacteriaceae seem to be key players of ex situ biomethanation processes, since both families dominated the methanogenic community of our enrichment culture.

The bacterial community (Figure 3) was an integral part of the microbial community because VFA were produced and consumed (Table 1). Acetate formation and consumption were mainly observed, which indicates homoacetogenesis and SAO. At the end of the enrichment (T6), the dominant phylum was Firmicutes (91\%) (Figure S4), which is consistent with previous findings [21], followed by 
the phylum Bacteroidetes (9\%). Cooperation and competition can be expected in $\mathrm{H}_{2}$ biomethanation systems, since the microbial community can be composed of hydrogenotrophic and acetotrophic methanogens, homoacetogenic bacteria, and syntrophic acetate-oxidizing bacteria (SAOB) [10,25], as well as chain-elongating, predatory and scavenger microorganisms. In the present study, acetotrophic methanogens were not present due to the mainly hydrogenotrophic seed sludge. In general, it is conceivable that strict acetotrophic methanogens (Methanothrix) coexist with homoacetogens in hydrogenotrophic communities. While a lower abundance of Firmicutes was reported in earlier studies [10,23], a similar abundance as in this study was found by other studies [25,52,53]. In contrast, Bacteroidetes was found to be the dominant phylum by another study [54].

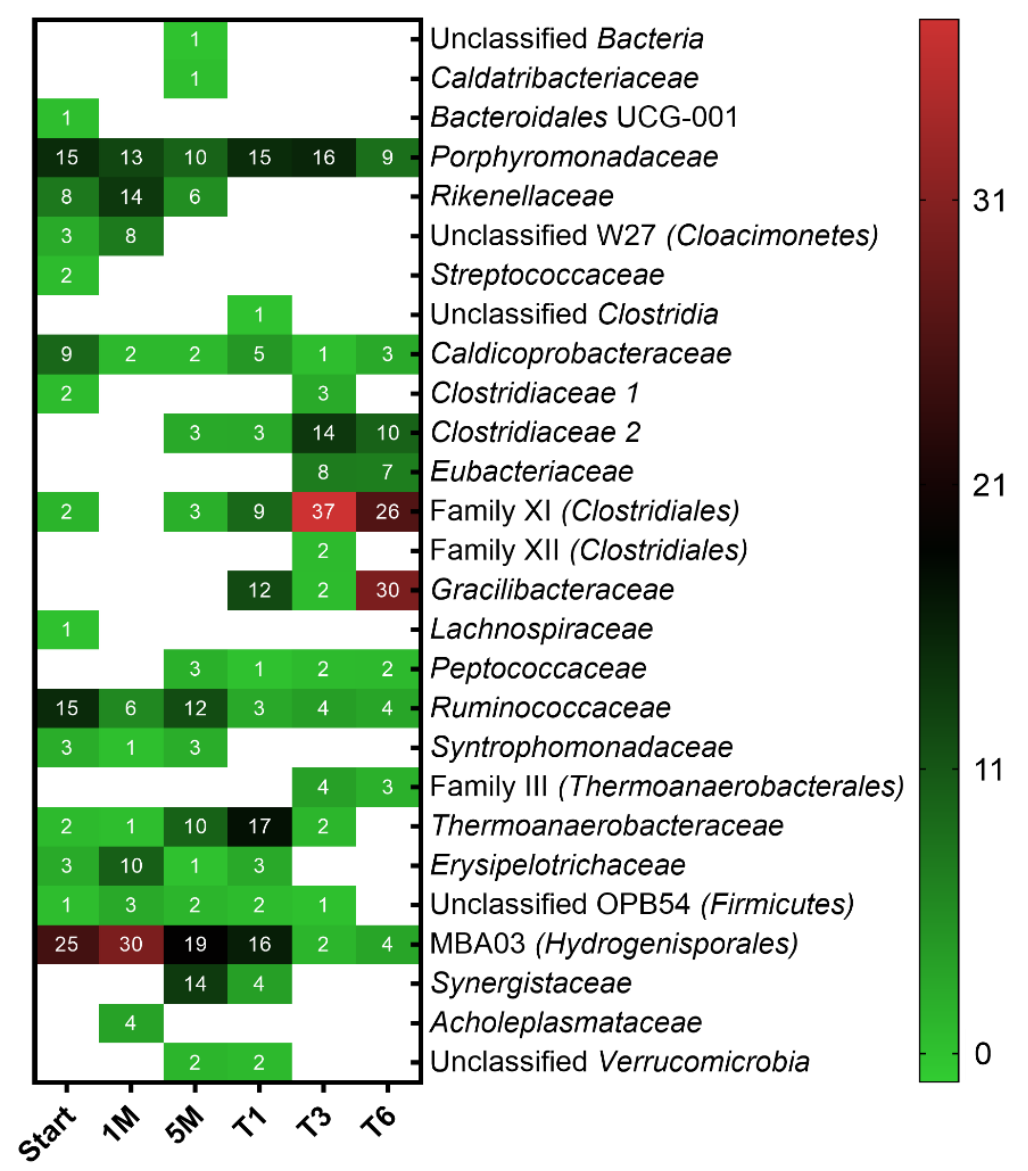

Figure 3. Bacterial community structure in different stages of the enrichment. Taxa with relative abundances less than $1 \%$ were filtered out from all samples. Numbers represent the relative abundance in percent and blank spaces indicate the absence of the respective taxa. Mean values of three biological replicates are presented for T1, T3 and T6 whereas single values are shown for Start, $1 \mathrm{M}$ and $5 \mathrm{M}$.

Throughout the enrichment, the abundance of the class Clostridia increased to $86 \%$ in the sixth transfer (Figure S5), whereas the classes Bacteroidia and OPB54 (Firmicutes), which were dominant in the inoculum, decreased in relative abundance to $9 \%$ and $5 \%$, respectively (Figure S5). The production of acetate from $\mathrm{H}_{2} / \mathrm{CO}_{2}$ (Table 1 ) indicated homoacetogenesis, which can be attributed to members of the Clostridiales that dominated the bacterial community throughout the enrichment (Figure S6). Some members of this order are crucial for homoacetogenesis [55] or SAO [56]. Homoacetogens and SAOB use the Wood-Ljungdahl pathway in the reductive or oxidative direction to produce acetate from $\mathrm{CO}_{2}$ or to oxidize acetate to $\mathrm{CO}_{2}$, respectively [55,57,58].

Mesophilic acetogens belong predominantly to the orders Clostridiales and Selenomonadales, whereas thermophilic acetogens belong to the order Thermoanaerobacterales [59]. Clostridiales and 
Thermoanaerobacterales were both present in the enrichment culture (Figure S6) and, together with the detection of acetate (Table 1), indicate the presence of acetogenic bacteria.

It is notable that, in T6, Lutispora was the predominant genus, with a relative abundance of $31 \%$ (Figure S7). The only described species of this genus is a thermophile not known to be a homoacetogen, which suggests that novel homoacetogenic species may be present in the enrichment culture and supports the need to further explore such unknown microbiota. This genus belongs to the clostridial family Gracilibacteraceae, which was found to be in low relative abundance in a former study [26]. Other genera such as MBA03 (Hydrogenisporales) (19\%), unclassified Family XI (Clostridiales) (15\%), Natronincola (10\%), unclassified Rikenellaceae (11\%), Fastidiosipila (8\%), Garciella (7\%), and Petrimonas $(5 \%)$ were also abundant in the bacterial community (Figure S7).

The acetate consumption could have occurred via SAO (e.g., by members of the classes Synergistia or OPB54 (Firmicutes) [60]), or could have been assimilated by acetogens and hydrogenotrophic methanogens to build biomass. The order Thermoanaerobacterales (class Clostridia) was present in lower abundance (3\% in T6), with its dynamic behavior in the second stage reaching similar levels as in the inoculum. Within this order, bacteria affiliated to the genus Gelria (family Thermoanaerobacteraceae) were found. This family comprises two species known as SAOB (Thermacetogenium phaeum and Tepidanaerobacter acetatoxydans), and Gelria was also suggested to be involved in SAO [61]. Although the relative abundance of this genus decreased drastically towards T6, a syntrophic association with the two most dominant methanogens (Methanoculleus and Methanobacterium) of the enrichment culture is conceivable. Hence, the low concentration of acetate, especially in $\mathrm{T} 6\left(\sim 123 \mathrm{mg} \mathrm{L}^{-1}\right)$ could be explained by the activity of SAOB or high acetate assimilation by the microbial community. The SAO function of the enrichment culture might be a shared task carried out by different phylotypes, since the biggest difference in the abundance of Gelria and Tepidanaerobacter genera was observed at the end of T1. Tepidanaerobacter syntrophicus was found in an ex situ biomethanation setup and it was suggested that this species was responsible for SAO [21]. Further investigations are needed by combining different omics approaches with improved isolation attempts in order to explore the largely unknown function of microorganisms represented only by sequence data.

\subsection{Microbial Resource Management for Selective Production of Methane}

\subsubsection{Effect of Medium Composition}

Our ex situ biomethanation experiment concomitantly enriched homoacetogenic bacteria and hydrogenotrophic methanogens in a similar manner to other studies $[10,19,24,30]$. It was argued that operational conditions are crucial to shaping a microbial community composition that, ultimately, will lead to a maximized $\mathrm{CH}_{4}$ yield [26]. The control of such parameters falls into the concept of microbial resource management for the selective production of any desired target molecule [12,62]. Here, we showed that selective $\mathrm{CH}_{4}$ production with enrichment cultures that contain both homoacetogenic bacteria and hydrogenotrophic methanogens is possible via controlling the medium composition. We explored the effect of several medium components on the products of the hydrogenotrophic enrichment culture in a separate set of experiments, with a focus on the products $\left(\mathrm{CH}_{4}\right.$ and VFA) and not the microbial community. The inocula for these experiments were derived from the last culture transfer of the enrichment phase (T11).

First, we assessed the effect of yeast extract in a medium containing cysteine- $\mathrm{HCl}$ as a reducing agent by comparing its cultivation in mineral medium with (medium A) or without yeast extract (medium B). Acetate was produced up to $\sim 5 \mathrm{mM}$ in both media, whereas formate was not produced at all (Figure 4A). However, medium A yielded 25\% more biomass than medium B after the first batch-cycle feeding ( $p=0.0031$ ), even though the yeast extract concentration was as low as $0.25 \mathrm{mg} \mathrm{L}^{-1}$ (Figure 4B). A cultivation broth with such low concentrations of yeast extract is considered a mineral medium [63]. 

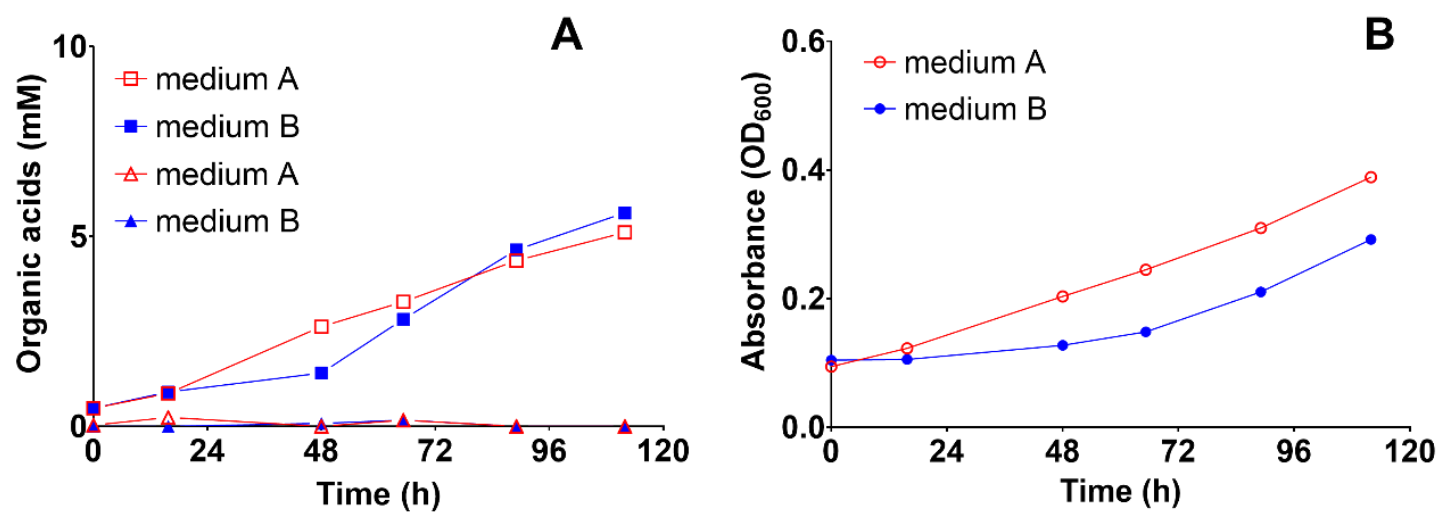

Figure 4. The effect of yeast extract on the production of acetic and formic acid and biomass during autotrophic feeding with $\mathrm{H}_{2} / \mathrm{CO}_{2}$ (80:20) in a 1-L bioreactors with medium A (containing $0.2 \mathrm{~g} \mathrm{~L}^{-1}$ yeast extract) and medium $\mathrm{B}$ (free of yeast extract but containing vitamins). Both media were reduced with cysteine-HCl. (A) Acetic acid and formic acid concentration profiles during the first batch cycle, and (B) microbial biomass growth, as measured by optical density at $600 \mathrm{~nm}$ during the first batch cycle. The experiments were conducted in two biological replicates with orbital shaking at $200 \mathrm{rpm}$. Each data point depicts the median and the range (invisible error bars are smaller than the symbol). Square: acetic acid, triangle: formic acid, circle: biomass.

In a second experiment, we tested the effect of the reducing agent on VFA formation in medium $\mathrm{B}$ (containing cysteine- $\mathrm{HCl}$ as reducing agent) and medium $\mathrm{C}$ (containing sodium sulfide as reducing agent). Acetate accumulated in both cultures with mediums $B$ and $C$, but after $\sim 300 \mathrm{~h}$ the concentration started to decrease and, concomitantly, formate concentration started to increase (Figure 5). This observation could indicate that formate formation occurred as a result of acetate degradation, meaning that it could be related to $\mathrm{SAO}$ (involving interspecies formate transfer). However, the possibility of direct formate production from $\mathrm{H}_{2} / \mathrm{CO}_{2}$ cannot be ruled out. The acetate concentration in medium $B$ was as high as $20 \mathrm{mM}$ (Figure $5 \mathrm{~A}$ ), whereas incubation for $\sim 500 \mathrm{~h}$ in medium $C$ yielded no acetate (Figure $5 \mathrm{~B}$ ). If cysteine- $\mathrm{HCl}$ is taken into account as an additional carbon source, up to $3.42 \mathrm{mM}$ acetate is expected, which is far less than the accumulated acetate concentration in medium B (Figure 5A), suggesting that acetate was mainly produced from $\mathrm{H}_{2} / \mathrm{CO}_{2}$. The final formate concentrations after $500 \mathrm{~h}$ were 2.4 and $2.9 \mathrm{mM}$ in the cultures with mediums B and C, respectively (Figure 5). After $500 \mathrm{~h}$ of operation, when the batch-cycle feeding was stopped, formate was rapidly consumed (data not shown). To our knowledge, experimental evidence of formate production in ex situ biomethanation has not been reported hitherto. Formate is an alternative electron donor for hydrogenotrophic methanogens [64] and a former study showed formate synthesis from $\mathrm{H}_{2} / \mathrm{CO}_{2}$ by bacteria [65]. Furthermore, pure cultures of hydrogenotrophic methanogens (Methanobacterium formicicum) or acetogenic bacteria transiently produced formate during $\mathrm{H}_{2} / \mathrm{CO}_{2}$ metabolism $[66,67]$. Hence, it can be inferred that homoacetogens, $\mathrm{SAOB}$ and hydrogenotrophic methanogens could have contributed to concomitant formate formation, along with methanogenesis. The observed formate concentration could be the result of dynamic production and consumption. The measurement of formate in micromolar concentrations is rather difficult [64]. This might explain why formate has not been reported in liquid products in other studies on ex situ biomethanation. Altogether, the results confirmed that formate was an intermediate during ex situ biomethanation; however, its exact mechanisms are still unclear. Reducing the sampling time intervals was important to allow formate determination in the broth. Biomass growth increased until the end of the experiment with medium $B$, whereas a plateau was reached after $\sim 375 \mathrm{~h}$ with medium $\mathrm{C}$ (biomass concentration in medium B was $24 \%$ higher than in medium C). This may be explained by sulfur depletion after prolonged incubation in medium $C$ because the medium was not replenished during the experimental period (the sulfur concentrations in medium $B$ and $C$ were 0.374 and $0.208 \mathrm{mM}$, respectively). The depletion of trace elements, which causes process imbalances because they are 
essential in enzyme complexes [68], may also explain the decreased $\mathrm{CH}_{4}$ production in both media after prolonged incubation. Although the biomass was less in medium $\mathrm{C}$, the $\mathrm{CH}_{4}$ concentration was higher than in medium B (32.5\%). Additionally, the $\mathrm{pH}$ drop after $500 \mathrm{~h}$ of fed-batch operation was not significantly different $(p<0.05)$ between the two media, as it decreased from $9.08 \pm 0.05$ and $9.03 \pm 0.05$ to $7.54 \pm 0.18$ and $7.73 \pm 0.04$ for medium $B$ and $C$, respectively.
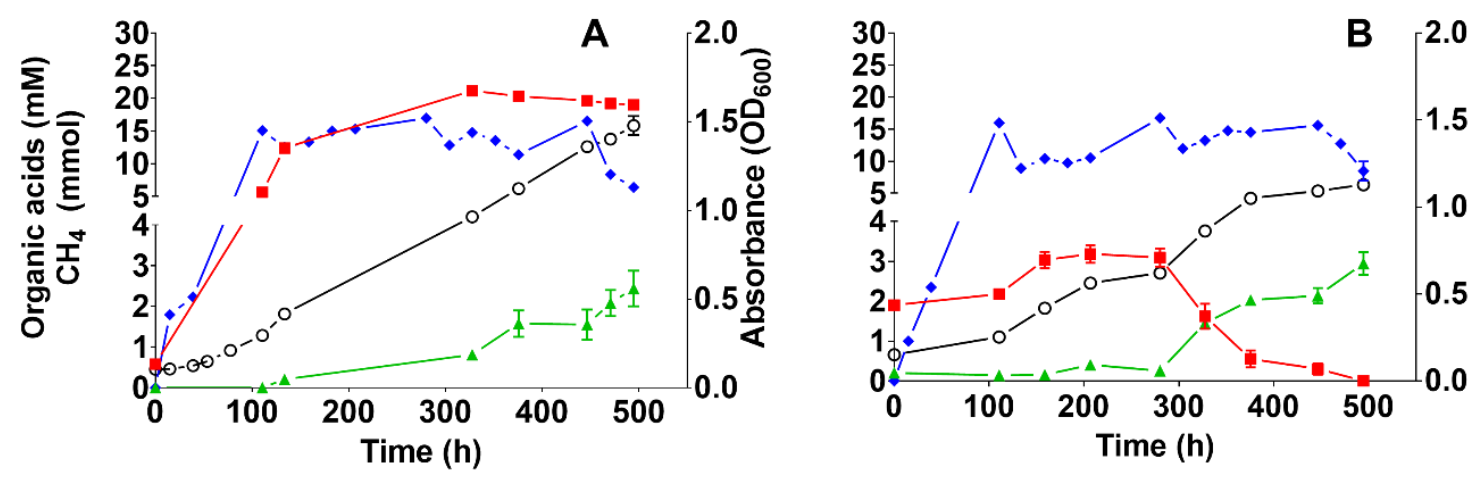

Figure 5. Effect of the reducing agent on the anaerobic conversion of $\mathrm{H}_{2} / \mathrm{CO}_{2}$ (80:20; fed-batch) in 1-L bioreactors following shaking at $200 \mathrm{rpm}$. (A) Medium B (mineral medium free of yeast extract, supplemented with vitamins and reduced with cysteine- $\mathrm{HCl}$ ), and $(\mathbf{B})$ medium $\mathrm{C}$ (prepared as medium B but containing sodium sulfide instead of cysteine- $\mathrm{HCl}$ as reducing agent; see Section 2.2). The experiments were conducted with two biological replicates and each data point depicts the median and range. Red square: acetic acid (mM), green triangle: formic acid (mM), blue diamond: $\mathrm{CH}_{4}(\mathrm{mmol})$, and black open circle: biomass.

\subsubsection{Effect of Stirring Intensity}

Next, the effect of the stirring intensity on the $\mathrm{CH}_{4}$ formation rate was analyzed. Improved mixing was reported to enhance the gas mass transfer and, hence, the $\mathrm{CH}_{4}$ formation rate $[3,17]$. As shown in Figure 6, the $\mathrm{CH}_{4}$ formation rate increased proportionally, with the stirring intensity up to a maximum of $\sim 9 \mathrm{mmol} \mathrm{L}^{-1} \mathrm{~h}^{-1}$ at $750 \mathrm{rpm}$. However, in this particle-free enrichment culture growing in a mineral medium, increasing the stirring intensity further to $\geq 1000 \mathrm{rpm}$ was detrimental (Figure 6) for both $\mathrm{CH}_{4}$ formation and $\mathrm{H}_{2}$ consumption rates. Although shaking exerts a different type of mixing than stirring does, our results are in line with a previous study, where shaking intensities of 200-250 rpm were already detrimental for biomethanation performed with sludge [28]. On the contrary, an in situ biomethanation study working with sludge reported improved gas mass transfer with a stirring intensity as high as $1000 \mathrm{rpm}$ [69]. This indicates that sludge can better resist shear forces caused by high stirring intensity than enrichment cultures, so that selecting a proper mixing intensity is dependent on the type of liquid matrix used as the biocatalyst. Under optimal conditions, the enrichment culture was capable of consuming the gaseous substrate within $24 \mathrm{~h}$ or less, similar to times reported elsewhere [17,70]. It is important to note that high shear (stirring speed $\geq 1000 \mathrm{rpm}$ ) may have a negative effect on the syntrophic interactions between bacteria and methanogens.

With an optimized medium composition (medium C) and mixing intensity (750 rpm), we obtained $\geq 97 \% \mathrm{CH}_{4}$ in the gas phase, which is comparable to other studies $[1,6]$. Although other measures may also affect the process performance, microbial resource management for biomethanation seems to be important when enriched mixed cultures are used as biocatalysts. 


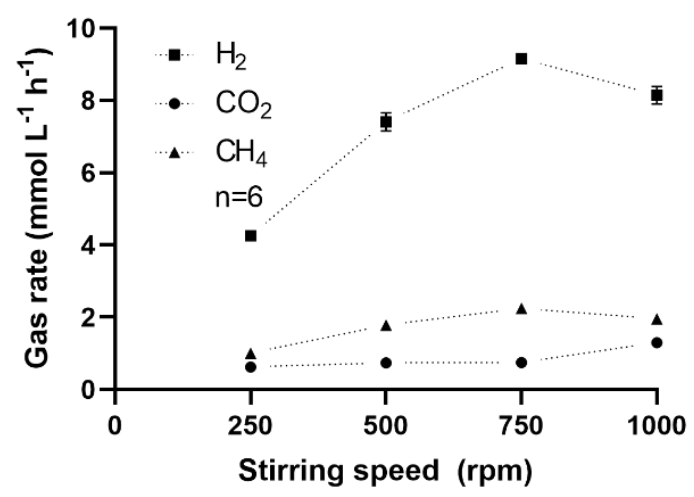

Figure 6. Effect of the stirring intensity on the consumption and formation rate of gases in a 1-L bioreactor with medium $C$. Bottles were pressurized at $\sim 2.2$ bar with a gas mixture of $\mathrm{H}_{2}(80 \%)$ and $\mathrm{CO}_{2}(20 \%)$. The rate for each stirring speed was repeated three times in duplicate biological bioreactors. Mean and standard deviation $(n=6)$ are shown (invisible error bars are smaller than the symbol).

\section{Conclusions}

We showed the enrichment of a hydrogenotrophic community that successfully produced grid quality $\mathrm{CH}_{4}(\geq 97 \%)$ through ex situ biomethanation. The methanogenic community was dominated by Methanoculleus and Methanobacterium. Microbial resource management allowed for the control of homoacetogenesis by directing the carbon and electron flows towards selective $\mathrm{CH}_{4}$ production by carefully defining the medium composition. The reducing agent played a pivotal role in controlling the production of acetate, while stirring intensities that were too high negatively affected ex situ biomethanation in a highly enriched particle-free community. Several bacterial taxa could be responsible for homoacetogenesis (mainly Clostridia). Thus, further investigations are needed to elucidate the physiological role of the most abundant bacterial genera in the hydrogenotrophic community.

Supplementary Materials: The following data are available online at http://www.mdpi.com/2076-2607/8/4/614/s1, Text S1: Media composition, Text S2: Chemicals and experimental operation, Table S1. Composition of the medium component 1, Table S2. Stock solutions used to supplement the media for different experiments, Table S3. Composition of stock solutions, Table S4 History of the culture transfers, Figure S1 Methane concentrations during successive culture transfers in medium A, Figure S2 Correlation between optical density and biomass concentration, Figure S3 Acetate concentration profile during one batch cycle feeding with T1, Figure S4 Bacterial relative abundance at phylum level for different stages of the enrichment, Figure S5 Bacterial relative abundance at class level for different stages of the enrichment, Figure S6 Bacterial relative abundance at order level for different stages of the enrichment, Figure S7 Bacterial relative abundance at genus level for different stages of the enrichment.

Author Contributions: Conceptualization: W.L., S.K. and M.N.; methodology: W.L., D.P., H.S. and M.N.; investigation: W.L.; formal analysis: W.L. and D.P.; data curation: W.L. and D.P.; writing-original draft preparation: W.L.; writing-review \& editing: D.P., S.K., H.S., H.H. and M.N.; visualization: W.L.; supervision: S.K., H.H. and M.N.; project administration: S.K. All authors have read and agreed to the published version of the manuscript.

Funding: This research received no external funding.

Acknowledgments: Ute Lohse is duly acknowledged for technical assistance in library preparation for MiSeq amplicon sequencing. Cloud computing facilities used for the analysis of the amplicon were provided by the BMBF-funded de.NBI Cloud within the German Network for Bioinformatics Infrastructure (de.NBI) (031A537B, 031A533A, 031A538A, 031A533B, 031A535A, 031A537C, 031A534A, 031A532B).

Conflicts of Interest: The authors declare no conflict of interest.

\section{References}

1. Lecker, B.; Illi, L.; Lemmer, A.; Oechsner, H. Biological hydrogen methanation-A review. Bioresour. Technol. 2017, 245, 1220-1228. [CrossRef] 
2. Schiebahn, S.; Grube, T.; Robinius, M.; Tietze, V.; Kumar, B.; Stolten, D. Power to gas: Technological overview, systems analysis and economic assessment for a case study in Germany. Int. J. Hydrogen Energy 2015, 40, 4285-4294. [CrossRef]

3. Luo, G.; Johansson, S.; Boe, K.; Xie, L.; Zhou, Q.; Angelidaki, I. Simultaneous hydrogen utilization and in situ biogas upgrading in an anaerobic reactor. Biotechnol. Bioeng. 2012, 109, 1088-1094. [CrossRef] [PubMed]

4. Verbeeck, K.; Buelens, L.C.; Galvita, V.V.; Marin, G.B.; Van Geem, K.M.; Rabaey, K. Upgrading the value of anaerobic digestion via chemical production from grid injected biomethane. Energy Environ. Sci. 2018, 11, 1788-1802. [CrossRef]

5. Muñoz, R.; Meier, L.; Diaz, I.; Jeison, D. A review on the state-of-the-art of physical/chemical and biological technologies for biogas upgrading. Rev. Environ. Sci. Biotechnol. 2015, 14, 727-759.

6. Angelidaki, I.; Treu, L.; Tsapekos, P.; Luo, G.; Campanaro, S.; Wenzel, H.; Kougias, P.G. Biogas upgrading and utilization: Current status and perspectives. Biotechnol. Adv. 2018, 36, 452-466. [CrossRef] [PubMed]

7. Villadsen, S.N.B.; Fosbøl, P.L.; Angelidaki, I.; Woodley, J.M.; Nielsen, L.P.; Møller, P. The Potential of Biogas; The Solution to Energy Storage. ChemSusChem 2019, 12(10), 2147-2153. [CrossRef]

8. Rittmann, S.; Seifert, A.; Herwig, C. Essential prerequisites for successful bioprocess development of biological $\mathrm{CH}_{4}$ production from CO 2 and H2. Crit. Rev. Biotechnol. 2015, 35, 141-151. [CrossRef]

9. Hoelzle, R.D.; Virdis, B.; Batstone, D.J. Regulation mechanisms in mixed and pure culture microbial fermentation. Biotechnol. Bioeng. 2014, 111, 2139-2154. [CrossRef]

10. Kougias, P.G.; Treu, L.; Benavente, D.P.; Boe, K.; Campanaro, S.; Angelidaki, I. Ex-situ biogas upgrading and enhancement in different reactor systems. Bioresour. Technol. 2017, 225, 429-437. [CrossRef]

11. Rittmann, S.K.-M.R. A Critical Assessment of Microbiological Biogas to Biomethane Upgrading Systems. In Biogas Science and Technology; Guebitz, G.M., Bauer, A., Bochmann, G., Gronauer, A., Weiss, S., Eds.; Springer International Publishing: Cham, Switzerland, 2015; pp. 117-135. ISBN 978-3-319-21993-6.

12. Verstraete, W.; Wittebolle, L.; Heylen, K.; Vanparys, B.; de Vos, P.; van de Wiele, T.; Boon, N. Microbial Resource Management: The road to go for environmental biotechnology. Eng. Life Sci. 2007, 7, 117-126. [CrossRef]

13. Mu, D.S.; Liang, Q.Y.; Wang, X.M.; Lu, D.C.; Shi, M.J.; Chen, G.J.; Du, Z.J. Metatranscriptomic and comparative genomic insights into resuscitation mechanisms during enrichment culturing. Microbiome 2018, 6, 1-15. [CrossRef] [PubMed]

14. Garcia, S.L. Mixed cultures as model communities: Hunting for ubiquitous microorganisms, their partners, and interactions. Aquat. Microb. Ecol. 2016, 77, 79-85. [CrossRef]

15. Stewart, E.J. Growing unculturable bacteria. J. Bacteriol. 2012, 194, 4151-4160. [CrossRef]

16. Kaeberlein, T.; Lewis, K.; Epstein, S.S. Quot; Microorganisms in Pure Culture in a Simulated Natural Environment. Science 2002, 296, 1127-1129. [CrossRef]

17. Luo, G.; Angelidaki, I. Integrated biogas upgrading and hydrogen utilization in an anaerobic reactor containing enriched hydrogenotrophic methanogenic culture. Biotechnol. Bioeng. 2012, 109, 2729-2736. [CrossRef]

18. Savvas, S.; Donnelly, J.; Patterson, T.P.; Dinsdale, R.; Esteves, S.R. Closed nutrient recycling via microbial catabolism in an eco-engineered self regenerating mixed anaerobic microbiome for hydrogenotrophic methanogenesis. Bioresour. Technol. 2017, 227, 93-101. [CrossRef]

19. Savvas, S.; Donnelly, J.; Patterson, T.; Chong, Z.S.; Esteves, S.R. Biological methanation of $\mathrm{CO}_{2}$ in a novel biofilm plug-flow reactor: A high rate and low parasitic energy process. Appl. Energy 2017, 202, 238-247. [CrossRef]

20. Guneratnam, A.J.; Ahern, E.; FitzGerald, J.A.; Jackson, S.A.; Xia, A.; Dobson, A.D.W.; Murphy, J.D. Study of the performance of a thermophilic biological methanation system. Bioresour. Technol. 2017, 225, 308-315. [CrossRef]

21. Bassani, I.; Kougias, P.G.; Treu, L.; Porté, H.; Campanaro, S.; Angelidaki, I. Optimization of hydrogen dispersion in thermophilic up-flow reactors for ex situ biogas upgrading. Bioresour. Technol. 2017, 234, 310-319. [CrossRef]

22. Alfaro, N.; Fdz-Polanco, M.; Fdz-Polanco, F.; Díaz, I. Evaluation of process performance, energy consumption and microbiota characterization in a ceramic membrane bioreactor for ex-situ biomethanation of $\mathrm{H}_{2}$ and $\mathrm{CO}_{2}$. Bioresour. Technol. 2018, 258, 142-150. [CrossRef] [PubMed] 
23. Corbellini, V.; Kougias, P.G.; Treu, L.; Bassani, I.; Malpei, F.; Angelidaki, I. Hybrid biogas upgrading in a two-stage thermophilic reactor. Energy Convers. Manag. 2018, 168, 1-10. [CrossRef]

24. Yun, Y.M.; Sung, S.; Kang, S.; Kim, M.S.; Kim, D.H. Enrichment of hydrogenotrophic methanogens by means of gas recycle and its application in biogas upgrading. Energy 2017, 135, 294-302. [CrossRef]

25. Bassani, I.; Kougias, P.G.; Treu, L.; Angelidaki, I. Biogas Upgrading via Hydrogenotrophic Methanogenesis in Two-Stage Continuous Stirred Tank Reactors at Mesophilic and Thermophilic Conditions. Environ. Sci. Technol. 2015, 49, 12585-12593. [CrossRef] [PubMed]

26. Rachbauer, L.; Beyer, R.; Bochmann, G.; Fuchs, W. Characteristics of adapted hydrogenotrophic community during biomethanation. Sci. Total Environ. 2017, 595, 912-919. [CrossRef]

27. Luo, G.; Angelidaki, I. Co-digestion of manure and whey for in situ biogas upgrading by the addition of $\mathrm{H}_{2}$ : Process performance and microbial insights. Appl. Microbiol. Biotechnol. 2013, 97, 1373-1381. [CrossRef]

28. Szuhaj, M.; Ács, N.; Tengölics, R.; Bodor, A.; Rákhely, G.; Kovács, K.L.; Bagi, Z. Conversion of $\mathrm{H}_{2}$ and $\mathrm{CO}_{2}$ to $\mathrm{CH}_{4}$ and acetate in fed-batch biogas reactors by mixed biogas community: A novel route for the power-to-gas concept. Biotechnol. Biofuels 2016, 9, 102. [CrossRef]

29. Mohd Yasin, N.H.; Maeda, T.; Hu, A.; Yu, C.P.; Wood, T.K. $\mathrm{CO}_{2}$ sequestration by methanogens in activated sludge for methane production. Appl. Energy 2015, 142, 426-434. [CrossRef]

30. Rachbauer, L.; Voitl, G.; Bochmann, G.; Fuchs, W. Biological biogas upgrading capacity of a hydrogenotrophic community in a trickle-bed reactor. Appl. Energy 2016, 180, 483-490. [CrossRef]

31. Díaz, I.; Pérez, C.; Alfaro, N.; Fdz-Polanco, F. A feasibility study on the bioconversion of $\mathrm{CO}_{2}$ and $\mathrm{H}_{2}$ to biomethane by gas sparging through polymeric membranes. Bioresour. Technol. 2015, 185, $246-253$. [CrossRef]

32. Voelklein, M.A.; Rusmanis, D.; Murphy, J.D. Biological methanation: Strategies for in-situ and ex-situ upgrading in anaerobic digestion. Appl. Energy 2019, 235, 1061-1071. [CrossRef]

33. Tian, H.; Fotidis, I.A.; Mancini, E.; Treu, L.; Mahdy, A.; Ballesteros, M.; González-Fernández, C.; Angelidaki, I. Acclimation to extremely high ammonia levels in continuous biomethanation process and the associated microbial community dynamics. Bioresour. Technol. 2018, 247, 616-623. [CrossRef] [PubMed]

34. Nikolausz, M.; Walter, R.F.H.; Sträuber, H.; Liebetrau, J.; Schmidt, T.; Kleinsteuber, S.; Bratfisch, F.; Günther, U.; Richnow, H.H. Evaluation of stable isotope fingerprinting techniques for the assessment of the predominant methanogenic pathways in anaerobic digesters. Appl. Microbiol. Biotechnol. 2013, 97, 2251-2262. [CrossRef] [PubMed]

35. Lv, Z.; Leite, A.F.; Harms, H.; Glaser, K.; Liebetrau, J.; Kleinsteuber, S.; Nikolausz, M. Microbial community shifts in biogas reactors upon complete or partial ammonia inhibition. Appl. Microbiol. Biotechnol. 2019, 103, 519-533. [CrossRef]

36. Porsch, K.; Wirth, B.; Tóth, E.M.; Schattenberg, F.; Nikolausz, M. Characterization of wheat straw-degrading anaerobic alkali-tolerant mixed cultures from soda lake sediments by molecular and cultivation techniques. Microb. Biotechnol. 2015, 8, 801-814. [CrossRef]

37. Bonk, F.; Popp, D.; Weinrich, S.; Sträuber, H.; Becker, D.; Kleinsteuber, S.; Harms, H.; Centler, F. Determination of Microbial Maintenance in Acetogenesis and Methanogenesis by Experimental and Modeling Techniques. Front. Microbiol. 2019, 10,1-13. [CrossRef]

38. Klindworth, A.; Pruesse, E.; Schweer, T.; Peplies, J.; Quast, C.; Horn, M.; Glöckner, F.O. Evaluation of general $16 \mathrm{~S}$ ribosomal RNA gene PCR primers for classical and next-generation sequencing-based diversity studies. Nucleic Acids Res. 2013, 41, e1. [CrossRef]

39. Steinberg, L.M.; Regan, J.M. Phylogenetic comparison of the methanogenic communities from an acidic, oligotrophic fen and an anaerobic digester treating municipal wastewater sludge. Appl. Environ. Microbiol. 2008, 74, 6663-6671. [CrossRef]

40. Martin, M. Cutadapt removes adapter sequences from high-throughput sequencing reads kenkyuhi hojokin gan rinsho kenkyu jigyo. EMBnet.journal 2013, 17, 10-12. [CrossRef]

41. Bolyen, E.; Rideout, J.R.; Dillon, M.R.; Bokulich, N.A.; Abnet, C.C.; Al-Ghalith, G.A.; Alexander, H.; Alm, E.J.; Arumugam, M.; Asnicar, F.; et al. Reproducible, interactive, scalable and extensible microbiome data science using QIIME 2. Nat. Biotechnol. 2019, 37, 852-857. [CrossRef]

42. Callahan, B.J.; McMurdie, P.J.; Rosen, M.J.; Han, A.W.; Johnson, A.J.A.; Holmes, S.P. DADA2: High-resolution sample inference from Illumina amplicon data. Nat. Methods 2016, 13, 581-583. [CrossRef] [PubMed] 
43. McIlroy, S.J.; Kirkegaard, R.H.; McIlroy, B.; Nierychlo, M.; Kristensen, J.M.; Karst, S.M.; Albertsen, M.; Nielsen, P.H. MiDAS 2.0: An ecosystem-specific taxonomy and online database for the organisms of wastewater treatment systems expanded for anaerobic digester groups. Database 2017, 2017, 1-9. [CrossRef] [PubMed]

44. Fish, J.A.; Chai, B.; Wang, Q.; Sun, Y.; Brown, C.T.; Tiedje, J.M.; Cole, J.R. FunGene: The functional gene pipeline and repository. Front. Microbiol. 2013, 4, 1-14. [CrossRef] [PubMed]

45. RStudio Team. RStudio: Integrated Development for R; RStudio, Inc.: Boston, MA, USA, 2016.

46. R Core Team. R: A Language and Environment for Statistical Computing; R Foundation for Statistical Computing: Vienna, Austria, 2019.

47. Wickham, H. ggplot2: Elegant Graphics for Data Analysis; Springer: New York, NY, USA, 2016; ISBN 978-3-319-24277-4.

48. Kern, T.; Theiss, J.; Röske, K.; Rother, M. Assessment of hydrogen metabolism in commercial anaerobic digesters. Appl. Microbiol. Biotechnol. 2016, 100, 4699-4710. [CrossRef]

49. Shieh, J.S.; Whitman, W.B. Pathway of acetate assimilation in autotrophic and heterotrophic methanococci. J. Bacteriol. 1987, 169, 5327-5329. [CrossRef]

50. Goyal, N.; Padhiary, M.; Karimi, I.A.; Zhou, Z. Flux measurements and maintenance energy for carbon dioxide utilization by Methanococcus maripaludis. Microb. Cell Fact. 2015, 14, 1-9. [CrossRef]

51. Feist, A.M.; Scholten, J.C.M.; Palsson, B.; Brockman, F.J.; Ideker, T. Modeling methanogenesis with a genome-scale metabolic reconstruction of Methanosarcina barkeri. Mol. Syst. Biol. 2006, 2, 1-14. [CrossRef]

52. Treu, L.; Campanaro, S.; Kougias, P.G.; Sartori, C.; Bassani, I.; Angelidaki, I. Hydrogen-fueled microbial pathways in biogas upgrading systems revealed by genome-centric metagenomics. Front. Microbiol. 2018, 9, 1-16. [CrossRef]

53. Jensen, M.B.; Strübing, D.; de Jonge, N.; Nielsen, J.L.; Ottosen, L.D.M.; Koch, K.; Kofoed, M.V.W. Stick or leave-Pushing methanogens to biofilm formation for ex situ biomethanation. Bioresour. Technol. 2019, 291, 121784. [CrossRef]

54. Dupnock, T.L.; Deshusses, M.A. High-Performance Biogas Upgrading Using a Biotrickling Filter and Hydrogenotrophic Methanogens. Appl. Biochem. Biotechnol. 2017, 183, 488-502. [CrossRef]

55. Schuchmann, K.; Müller, V. Autotrophy at the thermodynamic limit of life: A model for energy conservation in acetogenic bacteria. Nat. Rev. Microbiol. 2014, 12, 809-821. [CrossRef] [PubMed]

56. Westerholm, M.; Moestedt, J.; Schnürer, A. Biogas production through syntrophic acetate oxidation and deliberate operating strategies for improved digester performance. Appl. Energy 2016, 179, 124-135. [CrossRef]

57. Diekert, G.; Wohlfarth, G. Metabolism of homoacetogens. Antonie Van Leeuwenhoek 1994, 66, $209-221$. [CrossRef] [PubMed]

58. Ljungdahl, L. The Autotrophic Pathway of Acetate Synthesis in Acetogenic Bacteria. Annu. Rev. Microbiol. 1986, 40, 415-450. [CrossRef]

59. Bengelsdorf, F.R.; Beck, M.H.; Erz, C.; Hoffmeister, S.; Karl, M.M.; Riegler, P.; Wirth, S.; Poehlein, A.; Weuster-Botz, D.; Dürre, P. Bacterial Anaerobic Synthesis Gas (Syngas) and $\mathrm{CO}_{2}+\mathrm{H}_{2}$ Fermentation. Adv. Appl. Microbiol. 2018, 103, 143-221.

60. Peng, J.; Wegner, C.E.; Bei, Q.; Liu, P.; Liesack, W. Metatranscriptomics reveals a differential temperature effect on the structural and functional organization of the anaerobic food web in rice field soil. Microbiome 2018, 6, 1-16. [CrossRef]

61. Mosbæk, F.; Kjeldal, H.; Mulat, D.G.; Albertsen, M.; Ward, A.J.; Feilberg, A.; Nielsen, J.L. Identification of syntrophic acetate-oxidizing bacteria in anaerobic digesters by combined protein-based stable isotope probing and metagenomics. ISME J. 2016, 10, 2405-2418. [CrossRef]

62. De Vrieze, J.; Boon, N.; Verstraete, W. Taking the technical microbiome into the next decade. Environ. Microbiol. 2018, 20, 1991-2000. [CrossRef]

63. Stams, A.J.M.; Van Dijk, J.B.; Dijkema, C.; Plugge, C.M. Growth of syntrophic propionate-oxidizing bacteria with fumarate in the absence of methanogenic bacteria. Appl. Environ. Microbiol. 1993, 59, 1114-1119. [CrossRef]

64. Schink, B.; Montag, D.; Keller, A.; Müller, N. Hydrogen or formate: Alternative key players in methanogenic degradation. Environ. Microbiol. Rep. 2017, 9, 189-202. [CrossRef] 
65. Woods, D.D. Hydrogenlyases: The synthesis of formic acid by bacteria. Biochem. J. 1936, 30, 515-51527. [PubMed]

66. Peters, V.; Janssen, P.H.; Conrad, R. Transient production of formate during chemolithotrophic growth of anaerobic microorganisms on hydrogen. Curr. Microbiol. 1999, 38, 285-289. [CrossRef]

67. Wu, W.M.; Hickey, R.F.; Jain, M.K.; Zeikus, J.G. Energetics and regulations of formate and hydrogen metabolism by Methanobacterium formicicum. Arch. Microbiol. 1993, 159, 57-65. [CrossRef]

68. Wintsche, B.; Glaser, K.; Sträuber, H.; Centler, F.; Liebetrau, J.; Harms, H.; Kleinsteuber, S. Trace elements induce predominance among methanogenic activity in anaerobic digestion. Front. Microbiol. 2016, 7, 1-12. [CrossRef] [PubMed]

69. Agneessens, L.M.; Ottosen, L.D.M.; Voigt, N.V.; Nielsen, J.L.; de Jonge, N.; Fischer, C.H.; Kofoed, M.V.W. In-situ biogas upgrading with pulse $\mathrm{H}_{2}$ additions: The relevance of methanogen adaption and inorganic carbon level. Bioresour. Technol. 2017, 233, 256-263. [CrossRef]

70. Savvas, S.; Donnelly, J.; Patterson, T.; Chong, Z.S.; Esteves, S.R. Methanogenic capacity and robustness of hydrogenotrophic cultures based on closed nutrient recycling via microbial catabolism: Impact of temperature and microbial attachment. Bioresour. Technol. 2018, 257, 164-171. [CrossRef] [PubMed]

(C) 2020 by the authors. Licensee MDPI, Basel, Switzerland. This article is an open access article distributed under the terms and conditions of the Creative Commons Attribution (CC BY) license (http://creativecommons.org/licenses/by/4.0/). 